Review Article

COVID-19 - Special Issue

\title{
Host-shift as the cause of emerging infectious diseases: Experimental approaches using Drosophila-virus interactions
}

\author{
André C. Pimentel ${ }^{1 *}$ (D), Camila S. Beraldo ${ }^{1,2^{*}}$ (D) and Rodrigo Cogni ${ }^{1}$ (D) \\ ${ }^{1}$ Universidade de São Paulo, Instituto de Biociências, Departamento de Ecologia, São Paulo, SP, Brazil. \\ ${ }^{2}$ University of Helsinki, Organismal and Evolutionary Biology Research Program, Helsinki, Finland.
}

\begin{abstract}
Host shifts, when a cross-species transmission of a pathogen can lead to successful infections, are the main cause of emerging infectious diseases, such as COVID-19. A complex challenge faced by the scientific community is to address the factors that determine whether the cross-species transmissions will result in spillover or sustained onwards infections. Here we review recent literature and present a perspective on current approaches we are using to understand the mechanisms underlying host shifts. We highlight the usefulness of the interactions between Drosophila species and viruses as an ideal study model. Additionally, we discuss how cross-infection experiments - when pathogens from a natural reservoir are intentionally injected in novel host species - can test the effect cross-species transmissions may have on the fitness of virus and host, and how the host phylogeny may influence this response. We also discuss experiments evaluating how cooccurrence with other viruses or the presence of the endosymbiont bacteria Wolbachia may affect the performance of new viruses in a novel host. Finally, we discuss the need of surveys of virus diversity in natural populations using next-generation sequencing technologies. In the long term, these approaches can contribute to a better understanding of the basic biology of host shifts.
\end{abstract}

Keywords: Wolbachia, evolution, infection, cooccurrence, virus diversity.

Received: June 16, 2020; Accepted: September 28, 2020.

\section{Introduction}

In less than eight months, COVID-19 has spread from a few cases in Wuhan, China, to more than eighteen million people in almost everywhere in the world (Coronavirus Research Center, https://coronavirus.jhu.edu/map.html visited on August $\left.6^{\text {th }}, 2020\right)$. The disease is caused by a new humaninfecting virus, SARS-CoV-2 (Huang et al., 2020; Sironi et al., 2020). Phylogenetic analyses suggest that the natural host of this virus is likely bats, and that a possible wild animal sold at the Wuhan food market might be an intermediate host that helped transmission to humans (Lu et al., 2020). This is a classic example of an emerging infectious diseases (EID) - infections recognized in a host population for the first time (Morens and Fauci, 2013). The causes of the emergence of novel diseases are pointed out as due to multiple factors, which may involve socio-economic, environmental, and ecological components (Jones et al., 2008).

As in the case of COVID-19, a common cause of EID is the cross-species transmission of pathogens, which can lead to sustained onwards transmission. This successful pathogen emergence may occur through two different processes that vary in the level of pathogen adaptation following the colonization: host range expansion and host shift. Expansion of host range occurs when the jump increases the number of host species that the pathogen is able to infect without changing pathogen's

Send correspondence to Rodrigo Cogni. Universidade de São Paulo, Instituto de Biociências, Departamento de Ecologia, Rua do Matão 321, Trav. 14, Cid. Universitária, CEP 05508-090, São Paulo, SP, Brazil. E-mail: rodrigocogni@gmail.com.

*These authors contributed equally to this work. original gene pool (Thines, 2019). In turn, host shift takes place when the jump increases genetic differentiation in the pathogen, leading to specialization on the novel host (Longdon et al., 2014; Choi and Thines, 2015; Thines, 2019). In the case of SARS-CoV-2, the recognition of the virus receptor (angiotensin-converting enzyme 2, ACE2) is a feature shared with its relative viruses (e.g. SARS-CoV and the bat virus SL-CoV WIV16) that allowed the jump to humans (Yang et al., 2016; Lu et al., 2020). Furthermore, an amino acid residue substitutions in SARS-CoV-2 spike protein increases binding affinity to human ACE2 (Wang et al., 2020), what may indicate specialization on human host. Pathogen host shifts are often observed in humans, in which $60.3 \%$ of EID are zoonoses, changing mainly from wild animal reservoirs (Jones et al., 2008). Some examples include the acquired immunodeficiency syndrome (AIDS) pandemic caused by the human immunodeficiency virus (HIV), which jumped into humans from non-human primates (Sharp and Hahn, 2011; Faria et al., 2014), and Ebola, whose virus shifted from fruit bats to humans (Leroy et al., 2005).

One of the biggest current challenges to epidemiologists is to address the factors that guarantee the success of crossspecies transmissions, leading to host shifts. By addressing the mechanisms of host shift, it would be possible to understand what causes spillover infections (i.e. events with no or short onward transmission) and what leads to sustained infections, when the pathogen enters, replicates itself within and is transmitted between members of the new host species (Longdon et al., 2014; Engelstädter and Fortuna, 2019).This would allow scientists to anticipate potential epidemics places, 
reducing the economic, environmental and social burden. Predicting the spatiotemporal occurrence of a host shift is still challenging, as it may be linked to a multitude of variables ranging from host and pathogen geographic dispersion to changes in host phenotype and genetics (Woolhouse et al., 2005). Assessing the factors favoring host shifts and identifying potential susceptible taxa is crucial to novel emerging pathogen research as well as to mitigate their impacts (Woolhouse et al., 2005; Burbrink et al., 2017).

Here we discuss how experimental approaches can help our comprehension of mechanisms favoring host shifts. We highlight the usefulness of the interactions between Drosophila species and viruses as a study model and review recent advances and current methods being pursued. We claim that understanding the basic biology of host shifts is essential to prevent and deal with infectious diseases such as COVID-19.

\section{The advantages of the Drosophila-virus model}

Studied for more than a century, Drosophila melanogaster has become the most studied organism in many fields of biology. Most of its success as a model organism is due to its rapid generation time, small size, easy stock maintenance, and unrivaled availability of genetic and genomic tools (Powell, 1997). Another advantage of this model in many fields, including studies of host-virus interactions, is its high degree of evolutionary conservation with other animals (Hoffmann, 2003; Lemaitre and Hoffmann, 2007; Panayidou et al., 2014; $\mathrm{Xu}$ and Cherry, 2014). Many defense mechanisms against viruses in Drosophila are conserved in vertebrates, such as Toll, Imd, and Jak-Stat pathways (Lemaitre et al., 1996; Merkling and Van Rij, 2015; Marques and Imler, 2016). However, a disadvantage of this system is that some immune pathways are restricted to some taxa and are not directly comparable to Drosophila. For example, Drosophila lacks an adaptive immune system, an important response to several pathogens that ensures immunological memory in vertebrates (Flajnik and Kasahara, 2010).

There are well established protocols for experimental work on Drosophila-virus interactions (Merkling and Van Rij, 2015; Yang et al., 2019) and recent research has covered diverse aspects of host-virus biology. Studies have looked at the genetic architecture of resistance to virus infection, including the identification of many major effect genes that affect resistance and their mechanisms of antiviral action (Magwire et al., 2012; Cogni et al., 2016; Cao et al., 2017). Some works have performed experimental tests of host-shifts in a controlled phylogenetic design (Longdon et al., 2011, 2015). Drosophila has also been used as a model to understand the replication mechanisms of human viruses such as SARSCoV (Hughes et al., 2012). Additionally, research on the diversity of insect viruses, and the mechanisms that control virus infections, have the potential to discover new adaptations that can inspire the development of novel antiviral strategies by the pharmaceutical industry (Olmo et al., 2019).

\section{Experiments on host-shift}

Cross-infection experiments - when pathogens from a natural reservoir are intentionally injected into new host species - are used to simulate host shifts and have been described as fruitful practices to understand mechanisms underlying host-pathogen interactions (Figure 1). Although the enormous theoretical efforts done to uncover which factors lead to sustained or to short chain infections (Chabas et al., 2018; Bonneaud et al., 2019; Dallas et al., 2019; Engelstädter and Fortuna, 2019), we lack system-related information not observable in nature, such as the frequency of cross-species pathogen transmissions, and the likelihood of infection given the exposure of the host (Mollentze et al., 2020). Data of this nature are only obtained through experimental studies. In order to better evaluate the array of possible data resulting from cross-infection experiments, it is important to categorize the components of the interaction. Infection dynamics depends on host effects (e.g. susceptibility and defense mechanisms), pathogen effects (e.g. replication ability and virulence), and interaction effects, which is related to the synergy between host and pathogen inherent features (Mollentze et al., 2020).

Host susceptibility can be dismantled in a set of attributes specific to the species and/or the individual, such as genetics, immunity, microbiome, age and sex (Casadevall and Pirofski, 2017). Conversely, during an infection, hosts may use a combination of two different mechanisms to defend against pathogens, resistance and tolerance (Ayres and Schneider, 2012). Resistance is when there is an activation of host's immune system to control pathogen's replication, and tolerance, when the host is able to avoid a decrease in its own fitness without necessarily altering the parasite load (Schneider and Ayres, 2008; Ayres and Schneider, 2012; Medzhitov et al., 2012; Vale et al., 2016).

The susceptibility of potential hosts varies greatly within and between taxa, and a key factor predicting it is the phylogenetic relatedness among potential hosts (De Vienne et al., 2013; Longdon et al., 2014; Engelstädter and Fortuna, 2019). This phylogenetic influence may occur through phylogenetic distance effect or phylogenetic clade effect (Figure 1; Longdon et al., 2014, 2015). Phylogenetic distance effects suggest that a pathogen infection success decreases as the phylogenetic distance from the natural host increases (Longdon et al., 2014). In such case, taxa phylogenetically closer to the natural host are more likely to be infected (Corey and Waite, 2007; De Vienne et al., 2009). For instance, Longdon et al. (2011) examined the variation in persistence and replication of three sigma viruses, isolated from different species of Drosophila, in 51 Drosophilidae novel hosts. They demonstrated that the viruses' replication ability was negatively related to the phylogenetic distance from the donor host. Considering that in novel infections the virus requires adaptations to use the cellular machinery of the new host, and supposing such structural changes increase with evolutionary divergence time, shifts to phylogenetically more distant hosts will demand more adaptations. Hence, being less able to replicate themselves, those three sigma viruses presented lower viral titers in species phylogenetically distant from their natural host (Longdon et al., 2011).

Phylogenetic clade effects predict that pathogen infection success varies between different host clades, but is similar within them - i.e. a particular clade of hosts may have related susceptibility to the pathogen, independent of its 
C

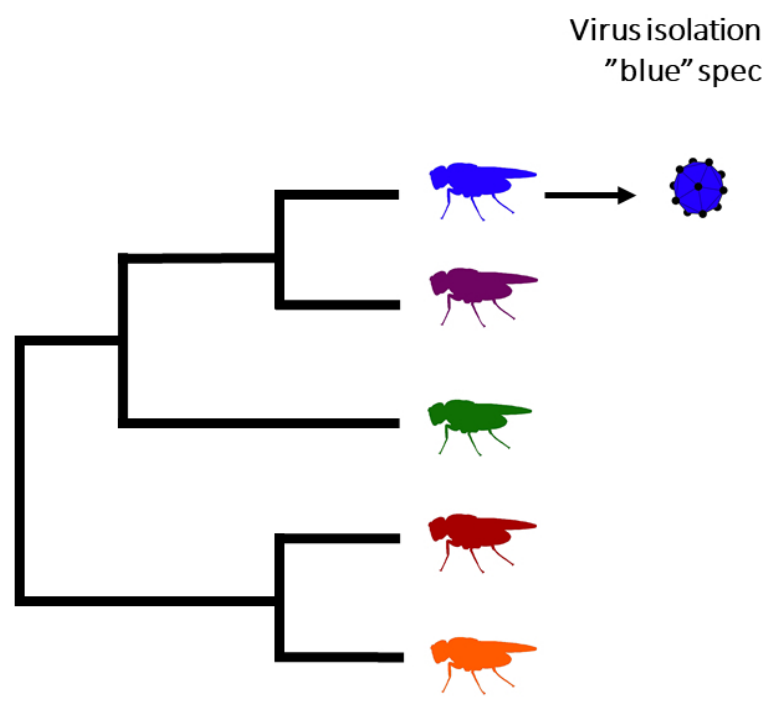

D

Phylogenetic

distance effect
E

Phylogenetic clade effect

Figure 1 - Cross-infection experiment and possible ways in which host phylogeny affects virus' shift. (A) Hypothetical host phylogeny. The flies' shading in various colors at the tips of the tree indicate different host species. (B) Isolation of a natural virus occurring in one of the host species (blue). (C) Artificial infection of the virus isolated in other host species (purple, green, red, and yellow). (D/E) Bars represent the virus infection success in each host species, and colors indicate the host species corresponding to each bar. (D) The virus' infection success decreases as the host relatedness to its natural host natural host species increases (phylogenetic distance effect). (E) The virus' infection success is not related to the phylogenetic proximity to its natural host species, but there are susceptible and resistant clades scattered across the host phylogeny (phylogenetic clade effect).

phylogenetic distance from the natural host (Longdon et al., 2014, 2015). This occurs when particular clades share some features that made them particularly resistant or susceptible to the pathogen (Longdon et al., 2014). For example, in a cross infection experiment using Drosophila C virus (DCV) and 48 species of Drosophila, Longdon et al. (2015) did not observe distance effect on viral load, but a pattern in which titers were clustering together across the host phylogeny. They hypothesized that physiological, immunity or molecular host features driving the virus infection success could be distributed heterogeneously among clades, generating "patches" of hosts with high susceptibility throughout the phylogeny.

Regarding the pathogen, virulence is a crucial trait to consider in host shift studies. Virulence is the cost in fitness a pathogen causes to its host due to infection (Read, 1994; Vale et al., 2016, 2018), and it may vary following a host shift, presenting high levels in particular species and leading to outbreaks and epidemics (Woolhouse et al., 2005; Jones et al., 2008). Initially, virulence was thought to be a direct consequence of parasite replication, being linked to the idea that the host-parasite interaction evolves towards avirulence, i.e. the pathogen does not cause a cost in fitness for the host anymore (Alizon et al., 2009). However, host susceptibility features, e.g. resistance or tolerance, may affect how virulent a pathogen could be, decoupling virulence and pathogen load measures (Gandon and Michalakis, 2000; Gandon, 2002).

Recent studies have looked at the interaction between host susceptibility and pathogen virulence. An elucidative example is the meta-analysis of cross-species tests that was developed by Mollentze et al. (2020). They analyzed the progression of rabies virus inoculations from bats and carnivores in other mammal species. This research showed that virus incubation period was longer in receptive hosts with higher body temperature. Interestingly, host body temperature for those groups analyzed were not correlated with phylogenetic distance, but tended to cluster across the phylogeny. They argue that mismatches between hosts physiological features and their evolutionary history may be influencing the infection progression and the success of cross-species transmissions.

As each host-pathogen association has its specificities and particular interaction results, it is imperative to compare, in a systematic manner, the effects of different infections on the fitness of both host and pathogen. This approach contributes to unravel factors driving the variation of host susceptibility, and pathogen's virulence and replication capacity. We are using this approach by isolating common viruses in field populations that vary in virulence, and manually injecting them into new hosts (as in Longdon et al., 2011, 2015). In the mid- and long-terms (hyphen and plural), such empirical data are useful to generate parameter distributions to model factors favoring host shifts, and to identify general rules promoting the emergence of infection diseases.

\section{Virus co-occurrence}

Viruses do not occur in isolation inside their hosts. After the cross-species transmission, the virus needs to interact with the natural viral community already present in the novel host. Prevalence of viruses in insects is far from negligible, and can reach more than $80 \%$ for a given virus, depending on the sampled locality (Webster et al., 2015). In a host-shift context, high prevalence of an endemic virus in the new host can directly affect the fitness of the virus that switched hosts (Figure 2). The co-occurrence of viruses may result in three 
different outcomes. First, there may be inhibition of viral replication if there is competition for host resources (viral interference) (Salas-Benito and De Nova-Ocampo, 2015). Second, if the presence of one virus compromises the host immune systems, the replication of the other virus may be favored (Kuwata et al., 2015). Third, there may be an apparent absence of fitness consequences (viral accommodation) (Salas-Benito and De Nova-Ocampo, 2015). Considering the specificities of the natural viral community inside potential hosts, it is essential to understand how the dynamics between different viruses affects the occurrence of host shifts.

The presence of a given virus can negatively affect a second infection if both depend on the same host resources, i.e. endemic viruses restrict cellular resources availability for the novel infecting virus. For instance, cell experiments with dual infections had shown that insect-specific viruses can inhibit the growth of Zika, dengue and La Crosse virus (Schultz et al., 2018). In Aedes aegypti mosquitos co-infected with two dengue viruses strains - DENV-1 and DENV-4 -, there was a competitive displacement of DENV1 by DENV-4, and only DENV-4 was detected in mosquito salivary gland, improving its transmission potential in a cooccurring event (Vazeille et al., 2016). This can have consequences on virus strains displacement in dengue epidemics (L'Azou et al., 2014). Therefore, this coinfection approach also provides insights for the arbovirus's transmission and prevalence, which currently impacts human health.

Regarding human respiratory viruses, there are epidemiological data supporting viral interference (e.g. Linde et al., 2009). A well-documented example is the interference between influenza viruses. Infection with influenza virus A(H1N1)pdm09 prevents subsequent infection with a different influenza type, causing temporary immunity following the first infection (Kelly et al., 2010; Laurie et al., 2015). Even though COVID data are preliminary, an equivalent viral interference may occurs, since SARS-CoV-2 patients are infrequently coinfected with other respiratory viruses (Blasco et al., 2020; Nowak et al., 2020).

An alternative scenario to competition is when a virus can benefit from natural infections. For example, when Culex tritaeniorhynchus cell line is previously infected by Culex flavivirus, subsequent infection with dengue virus enhances dengue viral titer in late stages of infection (Kuwata et al., 2015). This outcome is probably due to Culex flavivirus action on host antiviral defense. By expressing viral suppressor of RNAi, the virus decreases immune response and favors new infections or higher replication rates (Berry et al., 2009; Palmer et al., 2018). A third scenario is when virus fitness is not affected by cooccurring viruses. For instance, coinfection of $A$. aegypti cells with Zika and chikungunya viruses did not affect replication of the two viruses (Goertz et al., 2017). This lack of interference between both viruses may be explained by the different subcellular fractions occupied by these viruses during their replication (Goertz et al., 2017). Overall, interactions between viruses can lead to different outcomes in fitness of the new infecting virus, affecting the chances of a host-shift.

Surprisingly, these possible interaction effects of cooccurring viruses have not been tested in Drosophila melanogaster (Palmer et al., 2018). We propose an experimental approach with laboratory-controlled superinfections, in which individual flies are previously infected with a sub lethal dose of a virus, and afterwards infected with a second virus. The replication rate and virulence of the second virus indicate what would be expected in a host-shift in which the host has a high natural prevalence of a virus.

\section{Wolbachia virus blocking}

Not only can virus co-occurrence affect the result of a host-shift, but interactions with other organisms can also do so (Figure 2). A classic example is the presence of the bacterial endosymbiont Wolbachia which plays a multitude of effects on host fitness, such as protection against viral infection. Wolbachia is an alphaproteobacterium that lives within the cytoplasm of arthropod cells, and is maternally transmitted to the offspring. Until the recent past, it was viewed primarily as a parasite that manipulates host reproduction, most commonly by inducing cytoplasmic incompatibility (Bourtzis et al., 1996). Cytoplasmic incompatibility allows Wolbachia to invade populations by causing embryonic mortality when uninfected females mate with infected males, thus conferring a selective advantage to infected females (Turelli and Hoffmann, 1991; Werren et al., 2008).

More recently, basic research on Drosophila-virus interactions has discovered that Wolbachia can protect Drosophila species against infection by RNA viruses (Hedges et al., 2008; Teixeira et al., 2008). The applied potential of this finding to control arboviruses was soon noticed in the scientific community. Combined with Wolbachia's ability to invade populations due to cytoplasmic incompatibility, this provides a way to modify natural mosquito populations, turning them resistant to viral infections. Wolbachia has been transferred from Drosophila to the mosquito Aedes aegypti, where it limits the replication of arboviruses (Moreira et al., 2009). When Wolbachia infected mosquitoes were released into the wild, the bacterium spread through the mosquito populations by cytoplasmic incompatibility (Hoffmann et al., 2011; Walker et $a l ., 2011)$. Large field trials have shown that this approach can decrease dengue prevalence in human populations (Indriani et al., 2020; Ryan et al., 2020). A great advantage of this method to control arboviruses is that Wolbachia can block the replication of not only dengue virus, but also chikungunya, yellow fever, Zika and West Nile viruses (Moreira et al., 2009; Glaser and Meola, 2010; van den Hurk et al., 2012; Aliota et al., 2016).

The long-term success of this strategy depends on the knowledge of basic ecological and evolutionary aspects of virus blocking by Wolbachia. For example, there is great variation among Wolbachia lineages isolated from different Drosophila species in their ability to control virus infection (Martinez et al., 2014). We are expanding this study by investigating virus protection ability on a diverse set of Wolbachia lineages and testing if protection works with different viruses. Another important aspect that has not been completely understood yet is if Wolbachia protects against virus infection in wild populations of Drosophila. There is some evidence that this may not be the case. It seems that there was no association between virus incidence and Wolbachia presence in natural D. melanogaster populations (Webster et al., 2016; Shi et al., 
2018), but these studies may have low statistical power due to limited sample size. We plan to investigate this further to test if virus blocking in the natural Drosophila host occurs in wild populations or if it is only a laboratory phenomenon. If virus protection occurs in natural populations, it may have important ecological and evolutionary implications, such as changing the selective pressure on host resistance genes (Martinez et al., 2016; Faria et al., 2018). Finally, phylogenetic experiments on host-shift as described above, can be repeated with species that naturally host Wolbachia, to test how the presence of this endosymbiont may affect replication of the new virus on different host species (Figure 2).

\section{Virus diversity in natural populations}

Another essential piece of information to understand host shifts is the knowledge of virus natural host range and frequency of cross-species transmissions in wild populations. This can be obtained by comprehensive surveys of virus diversity in related hosts (Figure 3). Historically, virus diversity was only studied on disease-causing viruses in human and economically important species. Recently, however, the use of metagenomics in diverse taxonomic groups has revolutionized our view of the RNA virosphere as much more phylogenetically and genomically diverse than previously though (Shi et al., 2016; Obbard, 2018; Zhang et al., 2018, 2019). These new studies have uncovered the relative importance of virus-host codivergence versus host-shifts, and showed that host-shifts are common and most of the times not associated with diseases in the new host (Zhang et al., 2019).

In Drosophila, a seminal paper in 2015 (Webster et al., 2015) used metagenomics in wild $D$. melanogaster populations and identified more than 20 new viruses. They also used the presence of virus-derived 21 nucleotide (nt) small RNAs, a characteristic response of the RNAi antiviral defenses in Drosophila (Wang et al., 2006), to confirm that the virus sequences found were active virus infections. They found that viruses are common in wild populations, and also in laboratory stock lines and cell culture (by using publicly available RNA datasets). Webster et al. (2016) used a similar approach in six Drosophila species common in the UK and found 25 novel viruses. Interestingly, they found that few viruses are generalists, being able to infect different host species, and that many viruses shared among closely related species within the D. obscura group were less likely shared among more distantly related hosts. These results indicate a high diversity and incidence of viruses in natural populations and that most viruses are host specialists.

We are studying virus diversity in native drosophilid communities collected in the Atlantic Forest of Brazil. By using metagenomics in wild collected flies, we plan to discover new viruses and compare the virus diversity with the few previously studied Drosophila species (Webster et al., 2015, 2016). The Atlantic Forest drosophilid communities are highly diverse and contain species from different radiations forming a mix of common species that are close or distant related phylogenetically (Döge et al., 2008). This is the ideal situation to investigate host range and level of specialization of the different viruses and to contrast scenarios of codivergence or host shifts. This survey will likely give interesting virus candidates to be isolated and subsequently used in the experimental approaches described above.

\section{Conclusion}

Host shifts are complex phenomena affected by a multitude of factors and are the main cause of emerging infectious diseases such as COVID-19. Therefore, making predictions about the emergence of novel infections is extremely hard once factors driving this process are not entirely understood. In addition, we lack specific data essential for such forecast. We are applying diverse approaches using the interaction between Drosophila species and viruses, including cross-infection experiments in a phylogenetic controlled

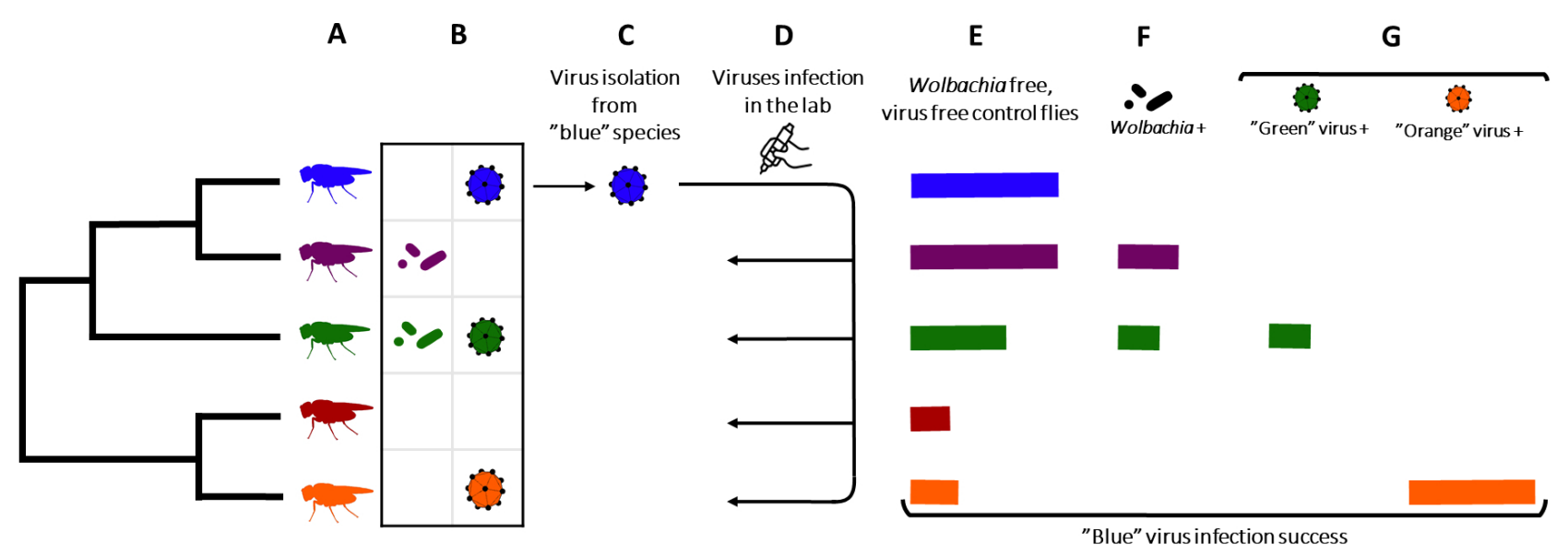

Figure 2 - Possible effects of Wolbachia and natural virus community on new hosts species on virus' shift. (A) Hypothetical host phylogeny. The flies' shading in various colors at the tips of the tree indicate different host species. (B) Two host species (purple and red) naturally carry the bacteria Wolbachia (first column). Three species (blue, green and orange) naturally carry three different viruses - blue, green and orange (second column). (C) Isolation of a natural virus occurring in one of the host species (blue). (D) Artificial infection of the virus isolated in other host species (purple, green, red, and yellow). (E-G) Bars represent the virus infection success in each host species, and colors indicate the host species corresponding to each bar. (E) Virus' infection success in laboratory control lines free of Wolbachia and other viruses. (F) When Wolbachia is present in the host, the blue virus' infection success is lower. $(\mathrm{G})$ When the green virus is present in a host, the blue virus' infection success is lower, but when the orange virus is present in the host, the blue virus' infection success is higher. 
A

Sample collection

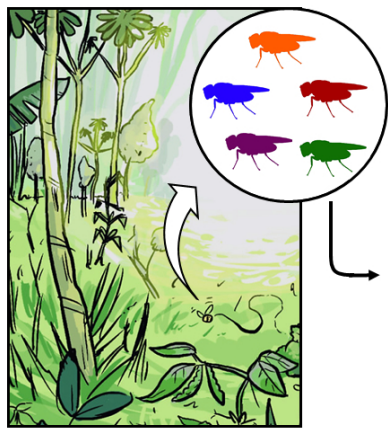

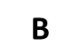

Nucleic acid

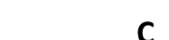

Metagenomic library construction

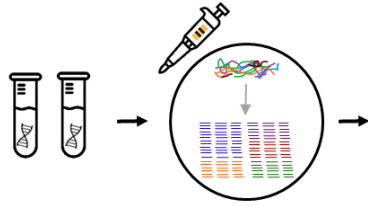

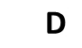

Sequencing

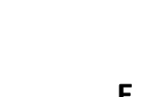

Virusscreening based on sequence similarity

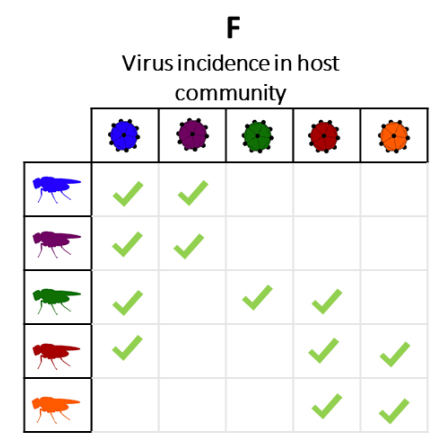

Figure 3 - Virus diversity in natural populations. (A) Fly natural populations are collected in the field and sorted into different species. (B) Nucleic acid extraction in the laboratory. (C) Metagenomic library construction. (D) Use of next generation sequencing of the libraries. (E) Bioinformatic work on virus screening based on sequence similarity. (F) Matrix showing incidence of each virus on each host species.

context, experiments testing the effects of virus cooccurrence and virus blocking by the bacteria Wolbachia, and surveys of virus diversity in natural populations using next-generation sequencing technologies. We argue that these practices provide a better understanding of the basic biology of host shifts, contributing to the identification of general rules favoring the emergence of infectious diseases in the long term.

\section{Acknowledgments}

Funding for this work was provided by São Paulo Research Foundation (FAPESP) (2013/25991-0, 2017/117748, 2016/09934-4 and 2015/08307-3), CNPq (154568/2018-0, 307015/2015-7 and 307447/2018-9), and a Newton Advanced Fellowship from the Royal Society.

\section{Conflict of Interest}

The authors declare that there is no conflict of interest that could be perceived as prejudicial to the impartiality of the reported research.

\section{Authors Contributions}

$\mathrm{RC}$ conceived the manuscript structure with inputs from ACP and CSB. ACP, CSB and RC wrote the manuscript. All authors read and approved the final version.

\section{References}

Aliota MT, Peinado SA, Velez ID and Osorio JE (2016) The $w$ Mel strain of Wolbachia reduces transmission of Zika virus by Aedes aegypti. Sci Rep 6:28792.

Alizon S, Hurford A, Mideo N and Van Baalen M (2009) Virulence evolution and the trade-off hypothesis: history, current state of affairs and the future. J Evol Biol 22:245-259.

Ayres JS and Schneider DS (2012) Tolerance of infections. Annu Rev Immunol 30:271-294.

Berry B, Deddouche S, Kirschner D, Imler J-L and Antoniewski C (2009) Viral suppressors of RNA silencing hinder exogenous and endogenous small RNA pathways in Drosophila. PLoS One 4:e5866.

Blasco ML, Buesa J, Colomina J, Forner MJ, Galindo MJ, Navarro J, Noceda J, Redon J, Signes-Costa J and Navarro D (2020) Co-detection of respiratory pathogens in patients hospitalized with Coronavirus viral disease-2019 pneumonia. J Med Virol 92:1799-1801.
Bonneaud C, Weinert LA and Kuijper B (2019) Understanding the emergence of bacterial pathogens in novel hosts. Philos Trans R Soc Lond B Biol Sci 374:20180328.

Bourtzis K, Nirgianaki A, Markakis G and Savakis C (1996) Wolbachia infection and cytoplasmic incompatibility in Drosophila species. Genetics 144:1063-1073.

Burbrink FT, Lorch JM and Lips KR (2017) Host susceptibility to snake fungal disease is highly dispersed across phylogenetic and functional trait space. Sci Adv 3:e1701387.

Cao C, Cogni R, Barbier V and Jiggins FM (2017) Complex coding and regulatory polymorphisms in a restriction factor determine the susceptibility of Drosophila to viral infection. Genetics 206:2159-2173.

Casadevall A and Pirofski L-A (2017) What is a host? Attributes of individual susceptibility. Infect Immun 86:e00636-17.

Chabas H, Lion S, Nicot A, Meaden S, Van Houte S, Moineau S, Wahl LM, Westra ER and Gandon S (2018) Evolutionary emergence of infectious diseases in heterogeneous host populations. PLoS Biol 16:e2006738.

Choi Y-J and Thines M (2015) Host jumps and radiation, not codivergence drives diversification of obligate pathogens. A case study in downy mildews and Asteraceae. PLoS One 10:e0133655.

Cogni R, Cao C, Day JP, Bridson C and Jiggins FM (2016) The genetic architecture of resistance to virus infection in Drosophila. Mol Ecol 25:5228-5241.

Corey SJ and Waite TA (2007) Phylogenetic autocorrelation of extinction threat in globally imperilled amphibians. Divers Distrib 14:614-629.

Dallas TA, Carlson CJ and Poisot T (2019) Testing predictability of disease outbreaks with a simple model of pathogen biogeography. R Soc Open Sci 6:190883.

De Vienne DM, Hood ME and Giraud T (2009) Phylogenetic determinants of potential host shifts in fungal pathogens. $\mathrm{J}$ Evol Biol 22:2532-2541.

De Vienne DM, Refrégier G, López-Villavicencio M, Tellier A, Hood ME and Giraud T (2013) Cospeciation vs host-shift speciation: Methods for testing, evidence from natural associations and relation to coevolution. New Phytol 198:347-385.

Döge JS, Valente VLS and Hofmann PRP (2008) Drosophilids (Diptera) from an Atlantic Forest area in Santa Catarina, Southern Brazil. Rev Bras Entomol 52:615-624.

Engelstädter J and Fortuna NZ (2019) The dynamics of preferential host switching: Host phylogeny as a key predictor of parasite distribution. Evolution 73:1330-1340. 
Faria NR, Rambaut A, Suchard MA, Baele G, Bedford T, Ward MJ, Tatem AJ, Sousa JD, Arinaminpathy N, Pépin J et al. (2014) The early spread and epidemic ignition of HIV-1 in human populations. Science 346:56-61.

Faria VG, Martins NE, Schlötterer C and Sucena É (2018) Readapting to DCV infection without Wolbachia: Frequency changes of Drosophila antiviral alleles can replace endosymbiont protection. Genome Biol Evol 10:1783-1791.

Flajnik MF and Kasahara M (2010) Origin and evolution of the adaptive immune system: Genetic events and selective pressures. Nat Rev Genet 11:47-59.

Gandon S (2002) Local adaptation and the geometry of host-parasite coevolution. Ecol Lett 5:246-256.

Gandon S and Michalakis Y (2000) Evolution of parasite virulence against qualitative or quantitative host resistance. Proc R Soc Lond B Biol Sci 267:985-990.

Glaser RL and Meola MA(2010) The native Wolbachia endosymbionts of Drosophila melanogaster and Culex quinquefasciatus increase host resistance to West Nile virus infection. PLoS One 5:e11977.

Goertz GP, Vogels CBF, Geertsema C, Koenraadt CJM and Pijlman GP (2017) Mosquito co-infection with Zika and chikungunya virus allows simultaneous transmission without affecting vector competence of Aedes aegypti. PLoS Negl Trop Dis 11:e0005654.

Hedges LM, Brownlie JC, O’Neill SL and Johnson KN (2008) Wolbachia and virus protection in insects. Science 322:702702.

Hoffmann JA (2003) The immune response of Drosophila. Nature 426:33-38.

Hoffmann AA, Montgomery BL, Popovici J, Iturbe-Ormaetxe I, Johnson PH, Muzzi F, Greenfield M, Durkan M, Leong YS, Dong Y et al. (2011) Successful establishment of Wolbachia in Aedes populations to suppress dengue transmission. Nature 476:454-457.

Huang C, Wang Y, Li X, Ren L, Zhao J, Hu Y, Zhang L, Fan G, Xu $\mathrm{J}, \mathrm{Gu} \mathrm{X}$ et al. (2020) Clinical features of patients infected with 2019 novel coronavirus in Wuhan, China. The Lancet 395:497-506.

Hughes TT, Allen AL, Bardin JE, Christian MN, Daimon K, Dozier KD, Hansen CL, Holcomb LM and Ahlander J (2012) Drosophila as a genetic model for studying pathogenic human viruses. Virology 423:1-5.

Indriani C, Tantowijoyo W, Rancès E, Andari B, Prabowo E, Yusdi D, Ansari MR, Wardana DS, Supriyati E, Nurhayati I et al. (2020) Reduced dengue incidence following deployments of Wolbachia-infected Aedes aegypti in Yogyakarta, Indonesia: A quasi-experimental trial using controlled interrupted time series analysis. Gates Open Res 4:50.

Jones KE, Patel NG, Levy MA, Storeygard A, Balk D, Gittleman JL and Daszak P (2008) Global trends in emerging infectious diseases. Nature 451:990-993.

Kelly H, Barry S, Laurie K and Mercer G (2010) Seasonal influenza vaccination and the risk of infection with pandemic influenza: A possible illustration of non-specific temporary immunity following infection. Euro Surveill 15:12-17.

Kuwata R, Isawa H, Hoshino K, Sasaki T, Kobayashi M, Maeda K and Sawabe K (2015) Analysis of mosquito-borne Flavivirus superinfection in Culex tritaeniorhynchus (Diptera: Culicidae) cells persistently infected with Culex Flavivirus (Flaviviridae). J Med Entomol 52:222-229.

L'Azou M, Taurel A-F, Flamand C and Quénel P (2014) Recent epidemiological trends of dengue in the French territories of the Americas (2000-2012): A systematic literature review. PLoS Negl Trop Dis 8:e3235.
Laurie KL, Guarnaccia TA, Carolan LA, Yan AWC, Aban M, Petrie S, Cao PX, Heffernan JM, McVernon J, Mosse J et al. (2015) Interval between infections and viral hierarchy are determinants of viral interference following influenza virus infection in a ferret model. J Infect Dis 212:1701-1710.

Lemaitre B and Hoffmann J (2007) The host defense of Drosophila melanogaster. Annu Rev Immunol 25:697-743.

Lemaitre B, Nicolas E, Michaut L, Reichhart J-M and Hoffmann JA (1996) The dorsoventral regulatory gene cassette spätzle/Toll/ cactus controls the potent antifungal response in Drosophila adults. Cell 86:973-983.

Leroy EM, Kumulungui B, Pourrut X, Rouquet P, Hassanin A, Yaba P, Délicat A, Paweska JT, Gonzalez J-P and Swanepoel R (2005) Fruit bats as reservoirs of Ebola virus. Nature 438:575-576.

Linde A, Rotzen-Ostlund M, Zweygberg-Wirgart B, Rubinova S and Brytting M (2009) Does viral interference affect spread of influenza? Euro Surveill 14:2-4.

Longdon B, Hadfield JD, Webster CL, Obbard DJ and Jiggins FM (2011) Host phylogeny determines viral persistence and replication in novel hosts. PLoS Pathog 7:e1002260.

Longdon B, Brockhurst MA, Russell CA, Welch JJ and Jiggins FM (2014) The evolution and genetics of virus host shifts. PLoS Pathog 10:e1004395.

Longdon B, Hadfield JD, Day JP, Smith SCL, McGonigle JE, Cogni R, Cao C and Jiggins FM (2015) The causes and consequences of changes in virulence following pathogen host shifts. PLoS Pathog 11:e1004728.

Lu R, Zhao X, Li J, Niu P, Yang B, Wu H, Wang W, Song H, Huang B, Zhu N et al. (2020) Genomic characterisation and epidemiology of 2019 novel coronavirus: Implications for virus origins and receptor binding. Lancet 395:565-574.

Magwire MM, Fabian DK, Schweyen H, Cao C, Longdon B, Bayer F and Jiggins FM (2012) Genome-wide association studies reveal a simple genetic basis of resistance to naturally coevolving viruses in Drosophila melanogaster. PLoS Genet 8:e1003057.

Marques JT and Imler J-L (2016) The diversity of insect antiviral immunity: Insights from viruses. Curr Opin Microbiol 32:71-76.

Martinez J, Longdon B, Bauer S, Chan YS, Miller WJ, Bourtzis K, Teixeira L and Jiggins FM (2014) Symbionts commonly provide broad spectrum resistance to viruses in insects: A comparative analysis of Wolbachia strains. PLoS Pathog 10:e1004369.

Martinez J, Cogni R, Cao C, Smith S, Illingworth CJR and Jiggins FM (2016) Addicted? Reduced host resistance in populations with defensive symbionts. Proc R Soc Lond B Biol Sci 283:20160778

Medzhitov R, Schneider DS and Soares MP (2012) Disease tolerance as a defense strategy. Science 335:936-941.

Merkling SH and Van Rij RP (2015) Analysis of resistance and tolerance to virus infection in Drosophila. Nat Protoc 10:1084-1097.

Mollentze N, Streicker DG, Murcia PR, Hampson K and Biek R (2020) Dynamics of viral index infections in novel hosts. bioRxiv:2020.04.09.033928.

Moreira LA, Iturbe-Ormaetxe I, Jeffery JA, Lu GJ, Pyke AT, Hedges LM, Rocha BC, Hall-Mendelin S, Day A, Riegler Met al. (2009) A Wolbachia symbiont in Aedes aegypti limits infection with dengue, Chikungunya, and Plasmodium. Cell 139:1268-1278.

Morens DM and Fauci AS (2013) Emerging infectious diseases: Threats to human health and global stability. PLoS Pathog 9:e1003467.

Nowak MD, Sordillo EM, Gitman MR and Paniz Mondolfi AE (2020) Co-infection in SARS-CoV-2 infected patients: Where are influenza virus and rhinovirus/enterovirus? J Med Virol 92:1699-1700.

Obbard DJ (2018) Expansion of the metazoan virosphere: Progress, pitfalls, and prospects. Curr Opin Virol 31:17-23. 
Olmo RP, Martins NE, Aguiar ERGR, Marques JT and Imler JL (2019) The insect reservoir of biodiversity for viruses and for antiviral mechanisms. An Acad Bras Cienc 91:e20190122.

Palmer W, Varghese F and Van Rij R (2018) Natural variation in resistance to virus infection in dipteran insects. Viruses 10:118.

Panayidou S, Ioannidou E and Apidianakis Y (2014) Human pathogenic bacteria, fungi, and viruses in Drosophila. Virulence 5:253-269.

Powell JR (1997) Progress and prospects in evolutionary biology: The Drosophila model. Oxford University Press, New York, 575 p.

Read AF (1994) The evolution of virulence. Trends Microbiol 2:73-76.

Ryan PA, Turley AP, Wilson G, Hurst TP, Retzki K, Brown-Kenyon J, Hodgson L, Kenny N, Cook H, Montgomery BL et al. (2020) Establishment of wMel Wolbachia in Aedes aegypti mosquitoes and reduction of local dengue transmission in Cairns and surrounding locations in northern Queensland, Australia. Gates Open Res 3:1547.

Salas-Benito JS and De Nova-Ocampo M (2015) Viral interference and persistence in mosquito-borne flaviviruses. J Immunol Res 2015:1-14.

Schneider DS and Ayres JS (2008) Two ways to survive infection: What resistance and tolerance can teach us about treating infectious diseases. Nat Rev Immunol 8:889-895.

Schultz MJ, Frydman HM and Connor JH (2018) Dual insect specific virus infection limits Arbovirus replication in Aedes mosquito cells. Virology 518:406-413.

Sharp PM and Hahn BH (2011) Origins of HIV and the AIDS pandemic. Cold Spring Harb Perspect Med 1:a006841-a006841.

Shi M, Lin X-D, Tian J-H, Chen L-J, Chen X, Li C-X, Qin X-C, Li J, Cao J-P, Eden J-S et al. (2016) Redefining the invertebrate RNA virosphere. Nature 540:539-543.

Shi M, White VL, Schlub T, Eden JS, Hoffmann AA and Holmes EC (2018) No detectable effect of Wolbachia wMel on the prevalence and abundance of the RNA virome of Drosophila melanogaster. Proc R Soc Lond B Biol Sci 285:20181165.

Sironi M, Hasnain SE, Rosenthal B, Phan T, Luciani F, Shaw M-A, Sallum MA, Mirhashemi ME, Morand S and GonzálezCandelas F (2020) SARS-CoV-2 and COVID-19: A genetic, epidemiological, and evolutionary perspective. Infect Genet Evol 84:104384.

Teixeira L, Ferreira A and Ashburner M (2008) The bacterial symbiont Wolbachia induces resistance to RNA viral infections in Drosophila melanogaster. PLoS Biol 6:e1000002.

Thines M (2019) An evolutionary framework for host shifts - jumping ships for survival. New Phytol 224:605-617.

Turelli M and Hoffmann AA (1991) Rapid spread of an inherited incompatibility factor in California Drosophila. Nature 353:440-442.

Vale PF (2018) Disease tolerance: Linking sickness behaviours to metabolism helps mitigate malaria. Curr Biol 28:R606-R607.

Vale PF, McNally L, Doeschl-Wilson A, King KC, Popat R, DomingoSananes MR, Allen JE, Soares MP and Kümmerli R (2016) Beyond killing. Evol Med Public Health 2016:148-157. van den Hurk AF, Hall-Mendelin S, Pyke AT, Frentiu FD, McElroy K, Day A, Higgs S and O'Neill SL (2012) Impact of Wolbachia on infection with chikungunya and yellow fever viruses in the mosquito vector Aedes aegypti. PLoS Negl Trop Dis 6:e1892.

Vazeille M, Gaborit P, Mousson L, Girod R and Failloux A-B (2016) Competitive advantage of a dengue 4 virus when co-infecting the mosquito Aedes aegypti with a dengue 1 virus. BMC Infect Dis 16:1-7.

Walker T, Johnson PH, Moreira LA, Iturbe-Ormaetxe I, Frentiu FD, McMeniman CJ, Leong YS, Dong Y, Axford J, Kriesner P et al. (2011) The wMel Wolbachia strain blocks dengue and invades caged Aedes aegypti populations. Nature 476:450-453.

Wang QH, Zhang YF, Wu LL, Niu S, Song CL, Zhang ZY, Lu GW, Qiao CP, Hu Y, Yuen KY et al. (2020) Structural and functional basis of SARS-CoV-2 entry by using human ACE2. Cell 181:894-904.e9.

Wang XH, Aliyari R, Li WX, Li HW, Kim K, Carthew R, Atkinson P and Ding SW (2006) RNA interference directs innate immunity against viruses in adult Drosophila. Science 312:452-454.

Webster CL, Waldron FM, Robertson S, Crowson D, Ferrari G, Quintana JF, Brouqui JM, Bayne EH, Longdon B, Buck AH et al. (2015) The discovery, distribution, and evolution of viruses associated with Drosophila melanogaster. PLoS Biol 13:e1002210.

Webster CL, Longdon B, Lewis SH and Obbard DJ (2016) Twentyfive new viruses associated with the Drosophilidae (Diptera). Evol Bioinform 12:13-25.

Werren JH, Baldo L and Clark ME (2008) Wolbachia: Master manipulators of invertebrate biology. Nat Rev Microbiol 6:741-751

Woolhouse MEJ, Haydon DT and Antia R (2005) Emerging pathogens: The epidemiology and evolution of species jumps. Trends Ecol Evol 20:238-244.

$\mathrm{Xu} \mathrm{J}$ and Cherry S (2014) Viruses and antiviral immunity in Drosophila. Dev Comp Immunol 42:67-84.

Yang S, Zhao Y, Yu J, Fan Z, Gong S-T, Tang H and Pan L (2019) Establishment of viral infection and analysis of host-virus interaction in Drosophila melanogaster. J Vis Exp 145:e58845.

Yang XL, Hu B, Wang B, Wang MN, Zhang Q, Zhang W, Wu LJ, Ge XY, Zhang YZ, Daszak P et al. (2016) Isolation and characterization of a novel bat coronavirus closely related to the direct progenitor of severe acute respiratory syndrome coronavirus. J Virol 90:3253-3256.

Zhang Y-Z, Shi M and Holmes EC (2018) Using metagenomics to characterize an expanding virosphere. Cell 172:1168-1172.

Zhang Y-Z, Chen Y-M, Wang W, Qin X-C and Holmes EC (2019) Expanding the RNA virosphere by unbiased metagenomics. Annu Rev Virol 6:119-139.

Associate Editor: Diogo Meyer

License information: This is an open-access article distributed under the terms of the Creative Commons Attribution License (type CC-BY), which permits unrestricted use, distribution and reproduction in any medium, provided the original article is properly cited. 